University of Wollongong

Research Online

Faculty of Engineering and Information

Faculty of Engineering and Information

Sciences - Papers: Part B

Sciences

2018

Teaching programming in common first year engineering: discipline insights applying a flipped learning problem-solving approach

Sasha Nikolic

University of Wollongong, sasha@uow.edu.au

Montserrat Ros

University of Wollongong, montse@uow.edu.au

David B. Hastie

University of Wollongong, dhastie@uow.edu.au

Follow this and additional works at: https://ro.uow.edu.au/eispapers1

Part of the Engineering Commons, and the Science and Technology Studies Commons

Research Online is the open access institutional repository for the University of Wollongong. For further information contact the UOW Library: research-pubs@uow.edu.au 


\title{
Teaching programming in common first year engineering: discipline insights applying a flipped learning problem-solving approach
}

\author{
Abstract \\ This paper investigated at the discipline level if flipped learning and engineering focused problem solving \\ could be used to overcome the difficulties associated with programming in a common first year \\ engineering curriculum. Perceived relevance of course material can impact self-efficacy and mindset \\ resulting in lower motivation to learn, effecting achievement. Literature suggests that flipped learning and \\ engineering problem solving can be combined to improve engagement, perceived relevance and \\ achievement. An effective implementation of flipped learning and engineering problem solving would be \\ reflected in student interest and achievement across all disciplines. A common first year engineering \\ course across nine engineering disciplines and a flexible cohort was implemented and analysed across \\ two years with 793 students. Success was measured across four objectives: 1) Appeal across disciplines; \\ 2) Achievement; 3) Future learning impact; and 4) Enrolment in computer engineering. Overall success \\ was found across the four objectives with no major negative impact across the first-year experience, \\ acceptable failure rates with achievement and student experience correlated with perceived discipline \\ relevance, and enrolment success in computer engineering. Further refinement is needed targeted at \\ improving the civil and mining student experience.

\section{Disciplines} \\ Engineering | Science and Technology Studies

\section{Publication Details} \\ S. Nikolic, M. Ros \& D. B. Hastie, "Teaching programming in common first year engineering: discipline \\ insights applying a flipped learning problem-solving approach," Australasian Journal of Engineering \\ Education, vol. 23, (1) pp. 3-14, 2018.
}




\title{
Teaching Programming in Common First Year Engineering: Discipline Insights Applying a Flipped Learning Problem Solving Approach
}

\author{
This paper investigated at the discipline level if flipped learning and engineering \\ focused problem solving could be used to overcome the difficulties associated with \\ programming in a common first year engineering curriculum. Perceived relevance of \\ course material can impact self-efficacy and mindset resulting in lower motivation to \\ learn, effecting achievement. Literature suggests that flipped learning and engineering \\ problem solving can be combined to improve engagement, perceived relevance and \\ achievement. An effective implementation of flipped learning and engineering problem \\ solving would be reflected in student interest and achievement across all disciplines. A \\ common first year engineering course across nine engineering disciplines and a flexible \\ cohort was implemented and analysed across two years with 793 students. Success was \\ measured across four objectives: 1) Appeal across disciplines; 2) Achievement; 3) \\ Future learning impact; and 4) Enrolment in computer engineering. Overall success was \\ found across the four objectives with no major negative impact across the first-year \\ experience, acceptable failure rates with achievement and student experience correlated \\ with perceived discipline relevance, and enrolment success in computer engineering. \\ Further refinement is needed targeted at improving the civil and mining student \\ experience.
}

Keywords: achievement, first-year engineering, flipped learning, MATLAB, motivation, problem solving, programming, relevance, student experience

\section{Introduction}

Programming is well established within the curriculum for computer, electrical, mechatronic, telecommunications and other related engineering disciplines due to graduates' needing to $\mathrm{read} / \mathrm{write}$ code and interface with hardware. For some engineering disciplines such as mechanical, civil and mining engineering the need to learn programming can be less obvious to the student, but still very important; highlighting the limited knowledge students have about the roles of engineers and possible career paths (Male and Bennett 2015). Programming also supports the development of problem solving, conceptualization of task order, and can be used as a tool for engineering analysis (Martínez et al. 2014; Oreta and Balili 2015). There is 
also a growing demand to learn the basics of coding to simply become a conversational programmer allowing for effective communication with technology experts (Chilana et al. 2015) and to develop digital literacy providing a pathway to engage with new technologies (Lee et al. 2016).

It is recognized that relevance as perceived by the student is an important motivator towards progress and achievement in programming courses (Forte and Guzdial 2005) as a student's mindset and self-efficacy can impact their approach to learning (Tek et al. 2018); something that needs to be recognized and overcome when teaching programming to the masses. Such issues with motivation needed careful consideration when the University of Wollongong (UOW) established a common first year curriculum in 2015 across nine disciplines of engineering (civil, computer, electrical, environmental, materials, mechanical, mechatronics, mining and telecommunications); providing a holistic understanding of the interconnection between different engineers, supporting confidence in the use of technology, and to provide flexibility in choice of degree. As part of the new common first year curriculum a first year programming course was deemed required, outlined in detail in Section 3. Implementing such a programming course faced numerous challenges with four objectives set to measure success. Firstly, the course would need to appeal to students across all disciplines to ensure success of the common structure. Secondly, the course would need to be taught using effective pedagogy that would motivate and aid students to learn, avoiding high failure rates in any one discipline. Thirdly, the course needed to include enough fundamentals not to impact future learning for programming related disciplines. Lastly, the balance between the first three objectives needed to ensure that the course would encourage student enrolment within the computer engineering discipline into the second year of the engineering degree.

This study explores the application of research in this area using a flipped learning engineering problem solving approach that balances the four objectives outlined. The 
hypothesis being that an effective implementation would be reflected in student interest and achievement across disciplines; requiring data analysis at the discipline level. Findings from this study are relevant to educators looking at approaches to improve programming courses that cater for a diverse range of engineering disciplines.

\section{Related Literature}

\subsection{First Year Programming Courses}

There is consensus that learning to program for the first time is difficult (Pears et al. 2007; Vihavainen et al. 2014) and has been correlated with high failure and dropout rates. Some of the difficulties in learning to program include decomposing a problem into subtasks; reading and understanding code; coming to terms with programming principles and routines; and synthesizing this new knowledge with existing knowledge (Koulouri et al. 2015). Such difficulties are even more so when the students find no relevance or interest in their learning, effecting their motivation to learn (Lahtinen et al. 2005; Liebenberg et al. 2015; Shim et al. 2017). In part, this is because students develop domain-specific implicit theories and selfbeliefs, leading students that find value in programming to use feedback to work harder and improve, while students that see little value struggle with the novelty and difficulty impacting their mindset, lowering confidence and approach to practice and learn (Hutchison-Green et al. 2008; Tek et al. 2018). This has resulted in many studies trying to determine how best to teach and understand what motivates first year students to ignite interest.

An early review of how best to design programming courses by Pears et al. (2007) focussed on literature that attempted to improve teaching effectiveness via changes in curricula, pedagogy, language choice, and tools for teaching; concluding that there is little systematic evidence to support any particular approach. Researchers have continued to try an array of approaches to improve the teaching effectiveness in delivering programming courses. 
A recent review by Vihavainen et al. (2014) attempted to quantify the impact on various interventions and found that no teaching approach works statistically significantly better than others. However, the study found that those that used relatable content with cooperative elements were most successful. This suggests that to make a common programming course effective, it needs to try and relate the content to as much of the student cohort as possible.

Common in computer science literature on first year programming is a debate whether traditional or object-oriented approaches should be used, but regardless the basics such as loops, variables, recursion and variable passing are fundamental to learning (Lahtinen et al. 2005). Moreover, studies have also looked at the value of using different programming languages, but overall it is important for students not to confuse the learning of programming with the learning of a programming language (Cazzola and Olivares 2016). In terms of motivation previous experience and interest have been shown to play a very important factor in engagement and achievement (Ashok Kumar et al. 2017; Kori et al. 2016). For this reason, there have been many attempts to build upon such findings by implementing strategies that showcase to non-computer science majors that programming is not a special talent, but something everyone can do with the right motivation and practice. Approaches have included visualization (Rubio et al. 2013) or game oriented learning (Bodnar et al. 2016) providing some insight to the potential ways programming can be taught to non-computer science students.

In terms of engineering students, evidence has been building that a successful way to teach programming is via discipline relevant engineering problems. Civil engineering problems using visual basic were successfully used to improve the relevance and experience of programming with a cohort of civil engineers in the Philippines (Oreta and Balili 2015). Problem solving with an engineering project was successful for motivating mechanical and mechatronics students in Canada (Hulls et al. 2015). Real world engineering problems were 
also found to be successful in teaching electrical engineering students in India (Anand et al. 2014). Work carried out by Hoffbeck et al. (2016) closely aligned to this study used MATLAB for a new common first year program targeted at civil, electrical and mechanical engineering students. Using a hands-on approach, students undertook programming exercises to tackle relevant engineering problems. The survey feedback on 72 students and assessment data suggested that this approach was successful and a good fit for an engineering common first year approach; however, the data was analysed collectively with no separation to compare student insights of the approach across disciplines. For example, did the possible positive feedback from electrical students out way the possible negative feedback from one of the other disciplines? A study by Radcliffe and Kumar (2016) confirmed that the general academic consensus with problem solving approaches to learning was positive, but warned that there could be a negative evaluation impact with weaker students. Together, these studies suggest that teaching programming to engineering students by using relevant engineering problems can lead to better engagement and achievement. Therefore, this paper builds upon such an approach and investigates the impact across a diverse cohort of engineering disciplines.

\subsection{Flipped Learning}

The traditional lecture orientated approach to teaching programming is increasingly being considered inappropriate and outdated leading to poor student engagement (Isong 2014). As an alternative, the Interactive, Constructive, Active and Passive (ICAP) framework moving students from passive to active and constructive to interactive engagement modes has been evidenced as an important process in increasing engagement and learning (Chi and Wylie 2014). The use of flipped learning approaches have been found successful in improving learning experiences for programming (Maher et al. 2015; Mok 2014; Salama et al. 2017) and other technical fields (Gardner et al. 2014; Mason et al. 2013; Zhang et al. 2016) by 
maximizing student engagement during class time, rearranging passive learning activities to occur outside of contact hours. This is generally done with students undertaking readings or watching videos at home, followed by pre-lecture quizzes reinforcing knowledge, and class time spent on interactive discussions or activities (O'Flaherty and Phillips 2015). Such an approach allows for the implementation of the ICAP framework encouraging active and interactive engagement. Therefore, due to the need to increase engagement and the hands-on nature of programming, a flipped learning approach to course delivery using an engineering problem solving core was selected as being highly appropriate.

\section{Course Development}

Traditionally, engineering programming for electrical, computer, mechatronics and telecommunications disciplines at UOW had been taught within the computer science department and internal data showed that teaching style, relevance and motivation were common issues raised by students each year. With students from other engineering disciplines also required to engage more heavily with programming, the literature encouraged the implementation of an engineering problem solving approach. That is, a fundamental goal was to show how programming was used in engineering, is relevant to all engineers, and how it could be used as a powerful tool to solve complex problems across all disciplines. The hypothesis being that an effective implementation would be reflected in student interest and achievement across disciplines.

A year long process in 2014 involved extensive discussions with key stakeholders across all nine engineering disciplines of what required inclusion in the first year and the makeup of the courses. An outcome of the discussions was a decision to redesign the structure of all engineering disciplines so that they accommodate a common first year program; leading to the development of new engineering courses and modified supporting physics and mathematics courses. One of the new engineering six-credit point courses deemed important 
for inclusion within the first year program was Engineering Computing and Analysis (ENGG100); formulated to provide students with an opportunity to develop a systematic approach to analyse engineering problems and create algorithms that solve real-world problems. The aim was to not only teach programming, but to also show how it is relevant across all disciplines through its use as a tool enabling the collection, management and analysis of data for engineering calculations and designs. While problem solving across all engineering disciplines was integral, a focus was placed on engineering dynamics.

In the old curriculum computer, electrical and telecommunications students undertook an introductory and then an advanced course in programming using $\mathrm{C}$ and $\mathrm{C}++$ in the first and second semester of first year. Mechatronics students undertook the introductory course. Civil, environmental and mining students undertook a computing course focused on using Microsoft Excel and basic scripting using visual basic in the second year. Mechanical and materials students undertook no core programming course. In the new curriculum all students undertook ENGG100 and the electrical, computer, telecommunications and mechatronics students undertook an advanced programming course using $\mathrm{C}$ and $\mathrm{C}++$ in the second year. Substantial negotiation was undertaken between the various disciplines as to the programming language to be used. Due to the courses focus on engineering problem solving, simplicity to execute programs, frequency of use in many other engineering courses, the availability of a campus and free student license, ability to interface with other languages, and it being recognized as one of the ten most used languages within the IEEE community (Cass 2015), MATLAB was favoured. This was further supported by the positive experiences outlined in the literature when using MATLAB in engineering and mathematics based contexts (Berenguel et al. 2016; Hoffbeck et al. 2016; Nyamapfene and Lynch 2016).

The content structure of the thirteen-week program is shown in Table I. The course structure followed the flipped learning model in which class time was designed to maximize 
engagement by integrating the ICAP framework to focus on active and interactive learning (Chi and Wylie 2014). Pre-lecture videos on programming in MATLAB and engineering mechanics were used to deliver passive knowledge, supported by pre-lecture quizzes. The benefit of the pre-lecture quiz was to try and ensure the students had a threshold level of understanding before attending the lecture or practical sessions. The pre-lecture quizzes provided feedback to students on their understanding of the passive content and if they needed to engage with additional resources provided. Moving the passive content out of class time provided the opportunity to reduce the lecture to one hour, freeing up contact hours for hands on activities. The reduction of the one hour lecture enabled an extra hour of class contact time to be transferred to the laboratory, further maximising the benefit of hands on activities. The structure of the lectures was changed to reinforce important concepts and to provide interactive examples.

\section{TABLE I: ENGG100 COURSE CONTENT STRUCTURE}

\begin{tabular}{|c|c|c|}
\hline Week & Content - Programming & Content - Engineering Dynamics \\
\hline 1 & Introduction to ENGG1OO and MATLAB & \\
\hline 2 & Data Types and Operators & \\
\hline 3 & Problem Solving and Flow Charts & \\
\hline 4 & Control Flow Constructs & \\
\hline 5 & Functions and Modular Programming & \\
\hline 6 & Graphics and Visualisation & Constant Acceleration in $1 D$ \\
\hline 7 & File Input and Output & Constant Acceleration in 2D - Projectile Motion \\
\hline 8 & Data Structures, Multi-dimensional Arrays & Rectilinear Motion - General Equations \\
\hline 9 & Advanced Programming Techniques & Rectilinear Motion - Erratic Motion \\
\hline 10 & Algorithms Programming & \\
\hline 11 & Modelling Engineering Applications with SIMULINK & Curvilinear Motion - Cartesian Equations \\
\hline 12 & Transitioning to Other Programming Languages & Curvilinear Motion - Normal \& Tangential Comps \\
\hline 13 & Revision & \\
\hline
\end{tabular}

The laboratory was divided into a two-hour practical and two-hour workshop. A range of studies provide evidence that undergraduates preferred to learn programming by example and practice (Lahtinen et al. 2005; Tan et al. 2009) which formed the basis of the 
practical component (active engagement mode) in which students would work through engineering problem solving examples from a MATLAB textbook (Hahn and Valentine 2013). It was expected that students would engage with the examples in their own time and use the time available within the practical session to gain feedback and support. The workshop component was designed for students to write their own code to solve engineering problems by integrating knowledge developed in the practical's, videos and lectures (constructive engagement mode), with such synthesise of knowledge and resources inductive to improving the student experience (Vial et al. 2015). A group assignment based on a 'realistic' engineering data set was used to tie all the knowledge together (interactive engagement mode) and showcase how programming is relevant across disciplines through its use as a tool enabling the collection, management and analysis of data for engineering calculations and designs. An example of a realistic data set was a group assignment that involved students being provided a data file containing raw track data of a race car. The group would need to identify the track the data set belonged to and produce several plots such as the normal and tangential acceleration of the race car using MATLAB, showcasing how engineering mechanics (and engineering data in general) related to and can benefit from programming. With the focus of this study centred on student interest and achievement across the engineering disciplines using this engineering focused approach, more in-depth information as to the flipped-learning delivery of the course can be accessed in Hastie et al. (2015).

The course was coordinated by a staff member representing each of the three departments of engineering, with the programming taught by the electrical, computer and telecommunication representative and the engineering dynamics by the mechanical, mechatronics and materials representative. The third coordinator provided a voice for the civil, mining and environmental content and supported the logistics of running the course. 
The laboratory sessions were predominately run by research students that had undergone extensive training as explained in Nikolic et al. (2015b) and were quality controlled using processes outlined in Nikolic et al. (2015a). The student to teacher ratio within the laboratory was approximately fifteen to one. The course was run in the first session of the first year engineering degree alongside Fundamentals of Engineering Mechanics, Materials in Design and Foundations of Engineering Mathematics. The second session included Electrical Systems, Engineering Design for Sustainability, Essentials of Engineering Mathematics and Physics for Engineers.

From the textbook (Hahn and Valentine 2013) students worked on example problems covering many fields of engineering, attempting to showcase the relevance of programming across all disciplines. However, the focus of learning and solving engineering problems was based on engineering mechanics. During the engineering mechanics component of the lectures, two or three worked examples were presented to the class, explaining how to interpret the question and extract the relevant data, orderly layout of the problem-solving process and presentation of final results. Some problems were solved in their entirety while others were partially solved, allowing students to continue the solution after class. An example workshop activity involved students developing a flowchart for generating motion data over time into an array and then implementing the work into MATLAB code.

\section{Method}

This study was conducted in 2015 and 2016, the first two years of the engineering common first year. This study was conducted in accordance to human research ethics approval UOW HREC 2017/222. Students that participated within the course structure included students enrolled in the nine engineering disciplines offered at the university as well as flexible students, those that wanted an opportunity to decide on a discipline. Due to the commonality, students could easily swap disciplines up until the start of the second year. The course also 
included elective students as well as students from the university's college that undertook a slightly different program and had different background skills. To fit the scope of the study these groups of students were excluded from the analysis. Table II outlines the final student numbers enrolled across the two years.

TABLE II: ENGG100 ENROLMENT NUMBERS BY DISCIPLINE

\begin{tabular}{|c|c|c|c|c|c|c|c|c|c|c|c|}
\hline 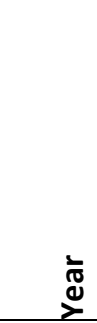 & $\begin{array}{l}\overline{\mathscr{J}} \\
\overline{\underline{Z}} \\
\frac{\mathrm{d}}{\mathrm{w}}\end{array}$ & 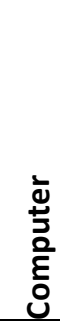 & 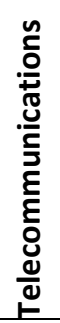 & 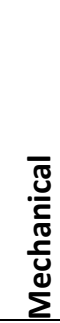 & 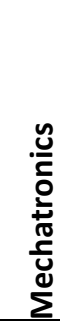 & 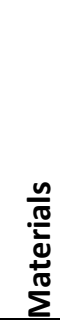 & $\bar{z}$ & 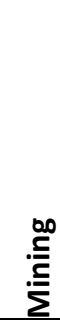 & 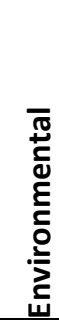 & $\begin{array}{l}\frac{0}{0} \\
\frac{0}{x} \\
\frac{0}{L}\end{array}$ & 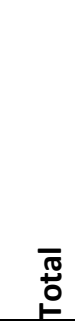 \\
\hline 2016 & 54 & 15 & 8 & 79 & 32 & 12 & 137 & 4 & 15 & 38 & 394 \\
\hline 2015 & 58 & 11 & 3 & 87 & 45 & 8 & 123 & 19 & 13 & 32 & 399 \\
\hline
\end{tabular}

Before the start of the year, at the midpoint of the year after results had been released, and at the end of the year after results had been released, the Faculty of Engineering and Information Sciences ran an anonymous Survey Monkey questionnaire to track the student experience of the entire common first year. The questions used from the survey in this study include:

1) Would you recommend this engineering degree to a friend based on your first-year experience?

2) Ranking across three surveys at different points in time: i) initial thoughts ii) end of first session iii) end of second session (end of year)

a) Rank in order the subjects you are looking forward to

b) Please rank the subjects in the order that was your favourite

c) Please rank the subjects in the order that was your favourite for the full first year The number of responses across each discipline and discipline weightings for the various iterations of the survey are outlined in Table III. This data along with student final grades across 2015 and 2016 was analysed anonymously according to discipline to examine any 
possible variations. Student final grades from a third year programming course was analysed to explore any potential long term impact. As outlined earlier, the pedagogical and student engagement aspects of the implementation which are outside the focus of this paper, can be found in Hastie et al. (2015).

\section{Results and Discussion}

\subsection{Appeal to students across disciplines}

The first objective was to ensure that the course would appeal to students across all disciplines to provide success of the common structure. The most important risk was that students overall, especially those that did not have to undertake programming in first year or at all before, may have had such a negative impact that it might have driven them away from engineering. At the end of each semester the students were asked the question 'Would you recommend this engineering degree to a friend based on your first-year experience?' In the old curriculum 'yes' received a 95\% response rate, and this continued in the new curriculum with $97 \%$ in 2015 and $95 \%$ in 2016 with no substantial difference across the three years. While this data does not tell anything about ENGG100 directly, it does suggest that the course did not discourage students away from an engineering major. It could simply be for example, that students could see the bigger picture and be driven to overcome particular courses in their quest to become an engineer.

The next set of analysis was to explore if this engineering approach had any impact on student interest on computer programming. Table III outlines student rankings (with 1 being ranked the highest) of the courses on offer based on initial perceptions before the start of session (ranked across all eight courses in the year), perceptions after the course had completed and final grades had been received (ranked across the four courses run in the first half of the year), and perceptions at the completion of the year (ranked across all eight 
courses). The data is displayed as the average ranking, number of responses and the discipline response weighting (percentage of students responding within any a specific engineering discipline).

TABLE III: ENGG100 STUDENT RANKING BY DISCIPLINE Ranking (Responses) [Discipline Response Weighting]

\begin{tabular}{|c|c|c|c|c|c|c|}
\hline \multirow[b]{2}{*}{ Discipline } & \multicolumn{3}{|c|}{2015} & \multicolumn{3}{|c|}{2016} \\
\hline & $\begin{array}{c}\text { Before } \\
\text { Session } \\
\text { (/8) }\end{array}$ & $\begin{array}{l}\text { Mid } \\
\text { Year } \\
(/ 4)\end{array}$ & $\begin{array}{c}\text { End of } \\
\text { Year } \\
(/ 8)\end{array}$ & $\begin{array}{c}\text { Before } \\
\text { Session } \\
(/ 8)\end{array}$ & $\begin{array}{l}\text { Mid } \\
\text { Year } \\
(/ 4)\end{array}$ & $\begin{array}{c}\text { End of } \\
\text { Year } \\
(/ 8)\end{array}$ \\
\hline All students & $\begin{array}{c}4(124) \\
{[31 \%]}\end{array}$ & $\begin{array}{c}3(102) \\
{[26 \%]}\end{array}$ & $\begin{array}{l}3(72) \\
{[18 \%]}\end{array}$ & $\begin{array}{c}3(103) \\
{[26 \%]}\end{array}$ & $\begin{array}{l}3(92) \\
{[23 \%]}\end{array}$ & $\begin{array}{l}3(66) \\
{[17 \%]}\end{array}$ \\
\hline Flexible Students & $\begin{array}{l}8(20) \\
{[63 \%]}\end{array}$ & $\begin{array}{l}3(17) \\
{[53 \%]}\end{array}$ & $\begin{array}{l}4(12) \\
{[38 \%]}\end{array}$ & $\begin{array}{l}5(23) \\
{[61 \%]}\end{array}$ & $\begin{array}{l}3(16) \\
{[42 \%]}\end{array}$ & $\begin{array}{l}4(10) \\
{[26 \%]}\end{array}$ \\
\hline Civil & $\begin{array}{l}4(25) \\
{[20 \%]}\end{array}$ & $\begin{array}{c}3(11) \\
{[9 \%]}\end{array}$ & $\begin{array}{l}2(19) \\
{[15 \%]}\end{array}$ & $\begin{array}{l}6(22) \\
{[16 \%]}\end{array}$ & $\begin{array}{l}4(15) \\
{[11 \%]}\end{array}$ & $\begin{array}{c}6(12) \\
{[9 \%]}\end{array}$ \\
\hline Computer & $\begin{array}{c}1(3) \\
{[27 \%]}\end{array}$ & $\begin{array}{c}1(4) \\
{[36 \%]}\end{array}$ & $\begin{array}{c}1(3) \\
{[27 \%]}\end{array}$ & $\begin{array}{c}2(3) \\
{[20 \%]}\end{array}$ & $\begin{array}{c}1(6) \\
{[40 \%]}\end{array}$ & $\begin{array}{c}1(4) \\
{[27 \%]}\end{array}$ \\
\hline Electrical & $\begin{array}{l}2(13) \\
{[22 \%]}\end{array}$ & $\begin{array}{l}1(5) \\
{[9 \%]}\end{array}$ & $\begin{array}{c}2(8) \\
{[14 \%]}\end{array}$ & $\begin{array}{l}2(11) \\
{[20 \%]}\end{array}$ & $\begin{array}{l}1(11) \\
{[20 \%]}\end{array}$ & $\begin{array}{l}2(12) \\
{[22 \%]}\end{array}$ \\
\hline Environmental & $\begin{array}{c}\text { N/A (0) } \\
{[0 \%]}\end{array}$ & $\begin{array}{l}2(1) \\
{[8 \%]}\end{array}$ & $\begin{array}{c}7(2) \\
{[15 \%]}\end{array}$ & $\begin{array}{c}4(8) \\
{[53 \%]}\end{array}$ & $\begin{array}{c}3(6) \\
{[40 \%]}\end{array}$ & $\begin{array}{c}4(3) \\
{[20 \%]}\end{array}$ \\
\hline Material & $\begin{array}{c}4(3) \\
{[38 \%]}\end{array}$ & $\begin{array}{c}3(4) \\
{[50 \%]}\end{array}$ & $\begin{array}{c}8(5) \\
{[63 \%]}\end{array}$ & $\begin{array}{c}3(4) \\
{[33 \%]}\end{array}$ & $\begin{array}{c}4(8) \\
{[67 \%]}\end{array}$ & $\begin{array}{c}7(2) \\
{[17 \%]}\end{array}$ \\
\hline Mechanical & $\begin{array}{l}5(21) \\
{[24 \%]}\end{array}$ & $\begin{array}{l}3(35) \\
{[40 \%]}\end{array}$ & $\begin{array}{l}5(12) \\
{[14 \%]}\end{array}$ & $\begin{array}{l}3(18) \\
{[23 \%]}\end{array}$ & $\begin{array}{l}3(15) \\
{[19 \%]}\end{array}$ & $\begin{array}{l}5(16) \\
{[20 \%]}\end{array}$ \\
\hline Mechatronics & $\begin{array}{l}2(13) \\
{[29 \%]}\end{array}$ & $\begin{array}{l}1(19) \\
{[42 \%]}\end{array}$ & $\begin{array}{c}2(9) \\
{[20 \%]}\end{array}$ & $\begin{array}{l}2(11) \\
{[34 \%]}\end{array}$ & $\begin{array}{c}1(8) \\
{[25 \%]}\end{array}$ & $\begin{array}{c}2(5) \\
{[16 \%]}\end{array}$ \\
\hline Mining & $\begin{array}{c}5(6) \\
{[32 \%]}\end{array}$ & $\begin{array}{c}4(5) \\
{[26 \%]}\end{array}$ & $\begin{array}{c}5(2) \\
{[11 \%]}\end{array}$ & $\begin{array}{c}8(1) \\
{[25 \%]}\end{array}$ & $\begin{array}{c}1(1) \\
{[25 \%]}\end{array}$ & $\begin{array}{c}8(1) \\
{[25 \%]}\end{array}$ \\
\hline Telecommunications & $\begin{array}{c}\text { N/A (0) } \\
{[0 \%]}\end{array}$ & $\begin{array}{c}1(1) \\
{[33 \%]}\end{array}$ & $\begin{array}{c}\text { N/A (0) } \\
{[0 \%]}\end{array}$ & $\begin{array}{c}1(2) \\
{[25 \%]}\end{array}$ & $\begin{array}{c}1(6) \\
{[75 \%]}\end{array}$ & $\begin{array}{c}1(1) \\
{[13 \%]}\end{array}$ \\
\hline
\end{tabular}

The data in Table III shows that initial student interest of ENGG100 aligns along stereotypical lines (disciplines generally associated with programming courses) with computer, electrical, mechatronics and telecommunications students ranking the subject favourably and other disciplines less favourably across both years. This finding is expected as it is natural for students to gravitate towards courses perceived most relevant to their interests, and align with their preconceptions as to what skill set their future career might involve (Male and Bennett 2015). The data also indicates that after the completion of the course and after completing all first-year courses that interest of ENGG100 did not improve as expected in non-programming based disciplines, remaining along stereotypical lines even with the focus 
changed to engineering problems. The ranking data provides some initial evidence that ENGG100 did not make students interested in programming based disciplines turn away from this field.

\subsection{Effective Pedagogy}

The second objective was to ensure effective pedagogy was applied that would motivate and aid students to learn. That is, it was important to develop an understanding if all students across disciplines thought the flipped learning, engineering problem solving approach was appropriate. Earlier work in Hastie et al. (2015) found that student engagement with the activities, and achievement in the course was positive, but neglected to analyse impact at the discipline level. To gain a deeper level of understanding at the discipline level it was important to analyse the reasons that students ranked ENGG100 high or low. Qualitative feedback provided by the students was used to discover common trends between disciplines in making ranking decisions. Students had the option within the anonymous Survey Monkey questionnaires to comment about the strengths of their highest ranked courses and weaknesses of their lowest ranked courses. This data is represented in Table IV and is a combination of feedback across the 2015 and 2016 cohorts with similar trends across both years. The table shows how the comments could be categorised, and the number of students making particular comments belonging to a particular discipline. Positive comments could be grouped into the categories: Practice based learning, the hands-on approach to learning programming; Challenging/Problem Solving/ Maths; Interesting/Enjoyable content or experience; appropriate Teaching/Structure/Support, as implemented through the flipped learning approach including the provided resources and feedback on all teaching staff; Relevant to my major/interests; Achievement; and, the engineering dynamics component. Negative responses could be grouped into a smaller set of categories based on: Difficulty; No interest/Not related to discipline; Approach to assessment; and, Teaching/Structure/Support. 

TABLE IV: ENGG100 QUALITATIVE FEEDBACK BY DISCIPLINE

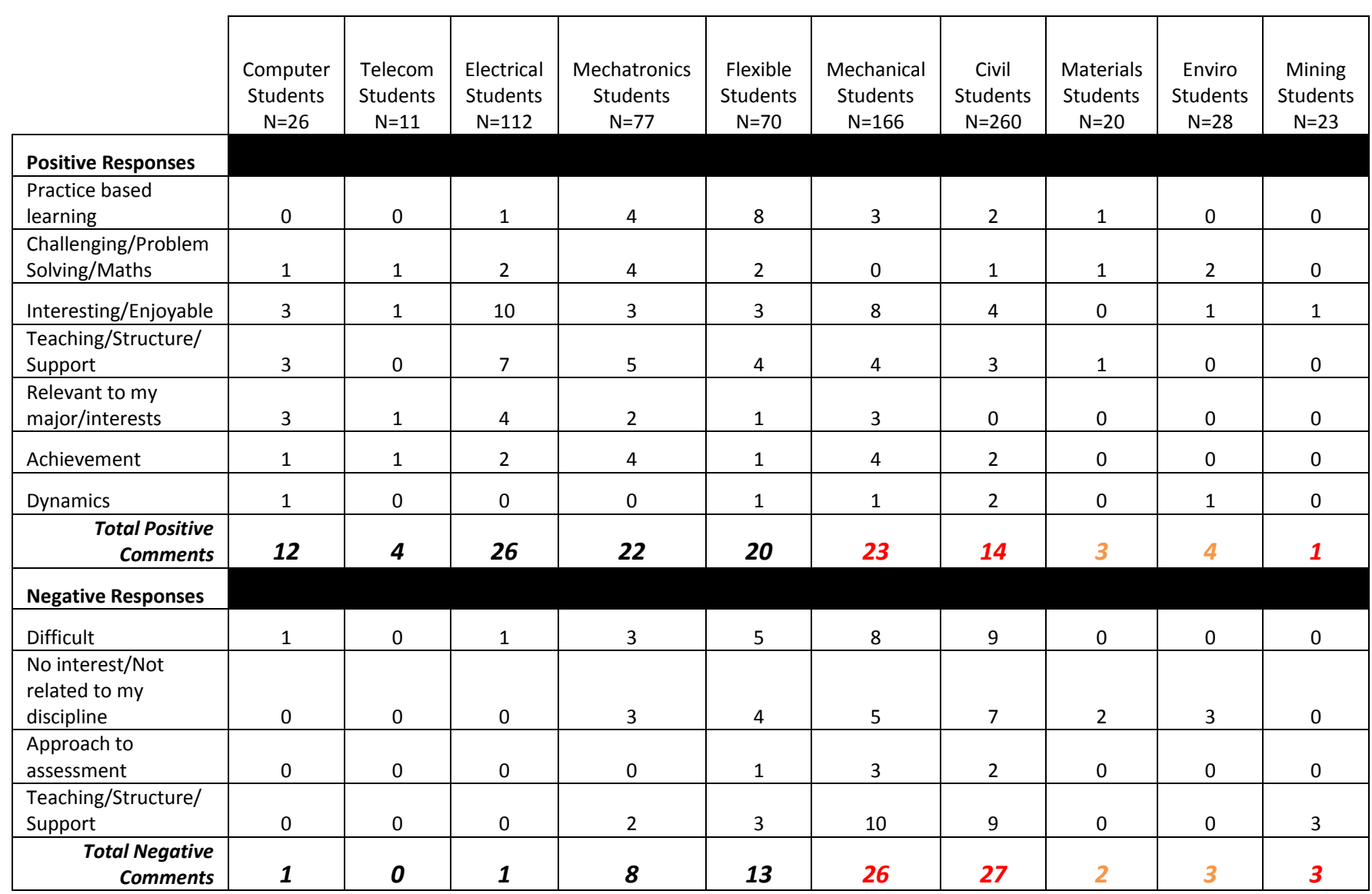

The comments represent a low number of students with 213 responses received from 793 students, noting that some comments could be broken into multiple categories; however, the response data does reflect the ranking data shown earlier in Table III. The disciplines that are stereotypically associated with programming (computer, electrical, telecommunications and mechatronics) have the highest ratio of positive comments to negative comments. These students found the content presented in ENGG100 interesting, relevant and appreciated the way the course was taught. On the contrary, students from the other disciplines had a greater percentage of students that struggled with the difficulty, failed to see the relevance of the course material to their discipline and struggled with the way the course was taught. Across the board, the hands-on nature of the course was a positive. The data suggests that feedback for this course when looked at holistically rather than at a discipline level could substantially vary depending on the weighting of student responses from each discipline, sending mixed 
messages towards the effectiveness of the implementation. For example with 260 civil engineers and only 26 computer engineering enrolled in the course over a two year period, such an imbalance in weighting and perceptions would skew the feedback towards the negative and hide the impact of different discipline perceptions.

A sample of feedback for each category is shown in Table V separated into two groups concentrated on the disciplines most associated with programming and those that are not. Interestingly, if it was not for the Mechatronics comments the only negative comments for the programming group would relate to difficulty. In effect, some of the comments from the Mechatronics students and others showcase the benefits of having a common first year with some students having false impressions of the skill sets needed within disciplines. The data from Tables IV and V provide an argument that the student experience within ENGG100 was influenced by the engineering discipline they belong to. That is, components of the implementation could be seen as a strength for some disciplines, but a weakness for other disciplines impacting the student experience. 
TABLE V: EXAMPLES OF FEEDBACK PROVIDED

\begin{tabular}{|c|c|c|}
\hline & $\begin{array}{c}\text { Computer, Electrical, Mechatronics \& } \\
\text { Telecommunications }\end{array}$ & $\begin{array}{c}\text { Civil, Environmental, Flexible, Materials, } \\
\text { Mechanical \& Mining }\end{array}$ \\
\hline \multicolumn{3}{|l|}{ Positive Responses } \\
\hline $\begin{array}{l}\text { Practice based } \\
\text { learning }\end{array}$ & "hands on approach" & "ENGG100's emphasis on the practical side" \\
\hline $\begin{array}{l}\text { Challenging/ } \\
\text { Problem solving/ } \\
\text { Maths }\end{array}$ & $\begin{array}{l}\text { "Loved the challenges that ENGG100 provided, } \\
\text { like a game trying to find the solution, loved the } \\
\text { subject" }\end{array}$ & $\begin{array}{l}\text { "challenged me most, which motivated me to } \\
\text { work, the others didn't stimulate me enough" }\end{array}$ \\
\hline Interesting/Enjoyable & $\begin{array}{c}\text { "I found the coding subject (ENGG100) interesting } \\
\text { as I have not done coding before and I really } \\
\text { enjoyed it" }\end{array}$ & "Interesting subject matter" \\
\hline $\begin{array}{l}\text { Teaching/ } \\
\text { Structure/ } \\
\text { Support }\end{array}$ & $\begin{array}{l}\text { "The way they structured the subject was genius, } \\
\text { the pre-lecture quizzes meant I already knew } \\
\text { briefly what the lecture would talk and I found this } \\
\text { helped me get the most out of the lectures and } \\
\text { constant assessment was incredibly effective in } \\
\text { gradual development of my skills, I hardly needed } \\
\text { to study by the end. Brilliant teachers too." }\end{array}$ & $\begin{array}{l}\text { "had more guidance with what to learn and what to } \\
\text { know" }\end{array}$ \\
\hline $\begin{array}{l}\text { Relevant to my } \\
\text { major/interests }\end{array}$ & $\begin{array}{l}\text { "ENGG100 is a computer course, and it is greatly } \\
\text { what I expected my degree to be like" }\end{array}$ & "Somewhat relevant to my degree and taste" \\
\hline Achievement & "my results" & $\begin{array}{l}\text { "I was relatively successful, and so was able to } \\
\text { enjoy them more" }\end{array}$ \\
\hline Dynamics & "Dynamics was done well" & $\begin{array}{l}\text { "dynamics from Engg100 on its own was my } \\
\text { favourite part" }\end{array}$ \\
\hline \multicolumn{3}{|l|}{ Negative Responses } \\
\hline Difficult & "Really hard programming" & "It was difficult and not enjoyable at all." \\
\hline $\begin{array}{l}\text { No interest/ } \\
\text { Not related to my } \\
\text { discipline }\end{array}$ & "no interest in MATLAB" (Mechatronics Only) & $\begin{array}{c}\text { "Programming as it has } 0 \text { to do with my chosen } \\
\text { discipline, I want to learn how to build mechanical } \\
\text { components I'm not interested in programming } \\
\text { what so ever" }\end{array}$ \\
\hline $\begin{array}{l}\text { Approach to } \\
\text { assessment }\end{array}$ & Not Applicable & $\begin{array}{c}\text { "ENGG100 was poorly set out too much } \\
\text { assessment every week no time to learn without } \\
\text { being assessed" }\end{array}$ \\
\hline $\begin{array}{l}\text { Teaching/ } \\
\text { Structure/ } \\
\text { Support }\end{array}$ & $\begin{array}{l}\text { "I found the questions for pre-lecture quizzes } \\
\text { irrelevant and trivial and I felt no support when I } \\
\text { needed it" (Mechatronics Only) }\end{array}$ & $\begin{array}{l}\text { "It was a subject that required most preparation, } \\
\text { taking too many hours to study for it. The lectures } \\
\text { were poor and teaching of it was very poor" }\end{array}$ \\
\hline
\end{tabular}

The strongest contrast between the two groups shown in Tables IV and V was

perceptions on the teaching and assessment structures; with the programming group providing

feedback as to how well everything was structured, and the other containing some students

claiming that the structure impacted their learning. This contrast could be interpreted to

support the literature in terms of self-efficacy and mindset (Tek et al. 2018) and the effect that

this has on students motivation to learn material of perceived relevance (Lahtinen et al. 2005;

Liebenberg et al. 2015; Shim et al. 2017) and at the speed in which they learn (Hutchison- 
Green et al. 2008). While motivation was not measured in the study, the feedback suggests that the flipped learning approach requires students to have academic discipline to learn passive material out of class and for students without the required motivation and interest this could have inhibited their learning. For students with the right motivation the feedback suggests that the flipped structure enabled learning. It could also be that introducing such a flipped structure at the commencement of first year with something as difficult as programming may have created a culture shock for many of the students coming straight out of high school compounding the motivation limitations. This was the first course in the engineering degree that the students became exposed to a flipped-learning pedagogy. To check for this, ENGG100 will be moved into the second semester of first year and analysed again. The feedback also indicates that the electrical, computer and telecommunications students had no issue in working on programming problems with a focus outside their discipline. It appears that they simply appreciated the value generated from learning how to program, regardless of the discipline based examples being used.

The next analysis was to confirm if the perceptions of ENGG100 were replicated in student achievement. Table VI outlines the average marks, standard deviation and failure rates for each of the disciplines in order of the highest. As expected, the students within the computer engineering discipline achieved the highest average marks and lowest failure rate. This was followed by electrical and mechatronics, but surprisingly the telecommunications cohort had the third lowest average contrasting with the earlier strong ranking data. However, a large discrepancy in performance across the two years questions the validity of this data due to the low number of students enrolled in a telecommunications degree. The civil and mining cohorts had the lowest averages, highest failure rates and could arguably be the disciplines with the lowest relevance to the course material; suggesting that the focus on engineering mechanics may be suitable for some of the disciplines, but not all. This achievement data 
correlates to the feedback presented in Table IV that students in disciplines such as civil and mining struggled with the teaching approach, structure, and support. While mechanical students also provided such feedback, the average grade was higher and failure rate lower which may correlate to the impact of the engineering mechanics content and the perceived relevance to mechanical engineers. As was discussed earlier, this provides some more support to the motivation vs perceived relevance vs mindset argument, possibly impacting the way the teaching staff need to deliver course content (Frymier and Shulman 1995).

TABLE VI: AVERAGE GRADES AND FAILURE RATES BY DISCIPLINE

\begin{tabular}{|c|c|c|c|c|c|c|c|c|c|c|c|c|}
\hline & \multicolumn{3}{|c|}{ Computer $\mathrm{N}=\mathbf{2 6}$} & \multicolumn{3}{|c|}{ Electrical $\mathrm{N}=112$} & \multicolumn{3}{|c|}{ Mechatronics N=77 } & \multicolumn{3}{|c|}{ Mechanical N=166 } \\
\hline & AVERAGE & SD & FAILS & AVERAGE & SD & FAILS & AVERAGE & SD & FAILS & AVERAGE & SD & FAILS \\
\hline 2016 & $77.8 \%$ & 9.7 & $0.0 \%$ & $69.9 \%$ & 18.2 & $5.6 \%$ & $63.5 \%$ & 19.4 & $9.4 \%$ & $70.1 \%$ & 18.2 & $10.1 \%$ \\
\hline 2015 & $72.5 \%$ & 11.1 & $0.0 \%$ & $72.3 \%$ & 16.7 & $3.4 \%$ & $74.8 \%$ & 16.2 & $4.4 \%$ & $65.5 \%$ & 18.0 & $9.2 \%$ \\
\hline \multirow[t]{3}{*}{ AVG } & $75.2 \%$ & 10.4 & $0.0 \%$ & $71.1 \%$ & 17.5 & $4.5 \%$ & $69.2 \%$ & 17.8 & $6.9 \%$ & $67.8 \%$ & 18.1 & $9.7 \%$ \\
\hline & \multicolumn{3}{|c|}{ Materials $\mathbf{N}=\mathbf{2 0}$} & \multicolumn{3}{|c|}{ Flexible $\mathrm{N}=70$} & \multicolumn{3}{|c|}{ Environmental $\mathbf{N}=\mathbf{2 8}$} & \multicolumn{3}{|c|}{ Telecoms $\mathbf{N}=11$} \\
\hline & AVERAGE & SD & FAILS & AVERAGE & SD & FAILS & AVERAGE & SD & FAILS & AVERAGE & SD & FAILS \\
\hline 2016 & $65.6 \%$ & 11.7 & $0.0 \%$ & $65.1 \%$ & 13.5 & $7.9 \%$ & $62.9 \%$ & 10.5 & $6.7 \%$ & $62.3 \%$ & 15.3 & $37.5 \%$ \\
\hline 2015 & $68.0 \%$ & 23.1 & $12.5 \%$ & $64.2 \%$ & 18.4 & $15.6 \%$ & $65.9 \%$ & 14.3 & $15.4 \%$ & $64.0 \%$ & 4.3 & $0.0 \%$ \\
\hline \multirow[t]{3}{*}{ AVG } & $66.8 \%$ & 17.4 & $6.3 \%$ & $64.7 \%$ & 16.0 & $11.8 \%$ & $64.4 \%$ & 12.4 & $11.1 \%$ & $63.2 \%$ & 9.8 & $18.8 \%$ \\
\hline & \multicolumn{3}{|c|}{ Civil $\mathbf{N}=\mathbf{2 6 0}$} & \multicolumn{3}{|c|}{ Mining $N=23$} & & & & & & \\
\hline & AVERAGE & SD & FAILS & AVERAGE & SD & FAILS & & & & & & \\
\hline 2016 & $58.7 \%$ & 20.1 & $17.5 \%$ & $53.2 \%$ & 8.5 & $25.0 \%$ & & & & & & \\
\hline 2015 & $61.9 \%$ & 19.1 & $14.6 \%$ & $52.2 \%$ & 22.7 & $31.6 \%$ & & & & & & \\
\hline AVG & $60.3 \%$ & 19.6 & $16.1 \%$ & $52.7 \%$ & 15.6 & $28.3 \%$ & & & & & & \\
\hline
\end{tabular}

\subsection{Future Learning Impact}

The next objective was to examine any possible long-term impact of introducing the common first year and the ENGG100 approach to programming on electrical, computer, mechatronics and telecommunications students. It is important to understand if the changes had a positive or negative impact on their future programming capability. These students undergo a thirdyear microcontroller course with a focus on assembly and C programming. Student achievement in the course was compared across the years 2015, 2016 and 2017. While 
comparing data across years is not highly reliable due to subtle changes that may occur in delivery, there had been no major changes to the course structure or content allowing for some insight to possible effects. Students in 2017 were the first common first year cohort to undertake the course. Only students completing the first three years at UOW were compared and it is important to note that some students may have swapped disciplines by third year.

This data from the microcontroller course is represented in Table VII and shows the average grade, standard deviation, number of students failing and whether a significant difference at the $5 \%$ level in grades between two years was recorded. The data indicates that average performance across the four disciplines remained relatively constant with no significant grade difference between the two curriculums; suggesting that this first-year approach is just as appropriate as the traditional curriculum. The low sample size may have had some impact on calculations.

TABLE VII: AVERAGE GRADES IN THIRD YEAR MICROCONTROLLER COURSE

\begin{tabular}{|c|c|c|c|c|c|c|c|c|c|c|}
\hline \multirow[b]{2}{*}{ Year } & \multicolumn{5}{|c|}{ Computer } & \multicolumn{5}{|c|}{ Electrical } \\
\hline & Students & Average & SD & Fails & $\begin{array}{l}\text { Stat } \\
\text { Diff }\end{array}$ & Students & Average & SD & Fails & $\begin{array}{l}\text { Stat } \\
\text { Diff } \\
\end{array}$ \\
\hline 2017 & 7 & $71.0 \%$ & 8.8 & 0 & No & 26 & $67.8 \%$ & 9.2 & 1 & No \\
\hline 2016 & 6 & $73.0 \%$ & 6.1 & 0 & No & 29 & $65.1 \%$ & 11.5 & 1 & No \\
\hline \multirow[t]{2}{*}{2015} & 3 & $63.6 \%$ & 15.1 & 1 & $\mathrm{~N} / \mathrm{A}$ & 32 & $58.3 \%$ & 10.9 & 3 & $\mathrm{~N} / \mathrm{A}$ \\
\hline & \multicolumn{5}{|c|}{ Telecommunications } & \multicolumn{5}{|c|}{ Mechatronics } \\
\hline Year & Students & Average & SD & Fails & $\begin{array}{l}\text { Stat } \\
\text { Diff }\end{array}$ & Students & Average & SD & Fails & $\begin{array}{l}\text { Stat } \\
\text { Diff }\end{array}$ \\
\hline 2017 & 3 & $72.3 \%$ & 10.6 & 0 & No & 27 & $68.1 \%$ & 11.1 & 1 & No \\
\hline 2016 & 3 & $57.0 \%$ & 12.0 & 0 & $\mathrm{~N} / \mathrm{A}$ & 30 & $59.0 \%$ & 15.5 & 5 & No \\
\hline 2015 & 0 & $\mathrm{~N} / \mathrm{A}$ & $\mathrm{N} / \mathrm{A}$ & 1 & $\mathrm{~N} / \mathrm{A}$ & 24 & $65.2 \%$ & 11.9 & 2 & $\mathrm{~N} / \mathrm{A}$ \\
\hline
\end{tabular}

\subsection{Enrolment in Computer Engineering}

The final objective was to deliver ENGG100 in a way that would encourage enrolments within the computer engineering discipline. The evidence examined earlier suggested that students associated with computer engineering found the approach enjoyable and performed well in assessment tasks. This positive data correlates with an increasing number of students 
remaining or choosing to study computer engineering in the second year. The enrolment numbers were 8, 10, 12 and 20 for the years 2014, 2015, 2016 and 2017 respectively; indicating that this objective has been met.

\section{Conclusion}

This study applied the principles of flipped learning and engineering problem solving with the goal of presenting programming as relevant to all engineers. The hypothesis being that an effective implementation would be reflected in student interest and achievement across all engineering disciplines. This was implemented in an engineering common first year course with nine disciplines and a flexible cohort.

The first objective was that the course would need to appeal to students across all disciplines to ensure success of the common structure. This was to ensure that students would not move away from engineering due to the curriculum change. The student recommendation rate of engineering remained high and constant between the new and old curriculum suggesting that there was no major impact in introducing a programming course across all engineering. The ranking data showed that student perceptions of programming remained along stereotypical lines for each discipline.

The second objective was that effective pedagogy would be needed to motivate and aid students to learn, avoiding high failure rates in any one discipline. The problem of a one size fits all solution is evident in the feedback. While the approach was received very strongly and praised by students in pro-programming related disciplines, feedback was at times very negative from others. In many cases, students from these disciplines claimed they could not keep up, or there was not enough support, while support networks and extra resources were provided. This provides further support to research focused on self-efficacy and mindset that value of learning impacts a student's perception of difficulty and their approach and 
motivation to learn (Lahtinen et al. 2005; Tek et al. 2018) and as a result the students that are most in need of support structures are the ones less likely to take advantage of them (Nikolic and Raad 2017; Nikolic et al. 2018). The relationship that relevance plays in motivating students to learn programming is possibly best seen within the civil and mining data; represented by lower achievement and higher failure rates and negative feedback. With minimal teaching from academic staff within the discipline and a heavy focus on engineering mechanics, these students could be asking themselves what does this course have to do with us? However, the performance and failure rates were acceptable. With a lack of motivation for students in some disciplines, the introduction of a flipped-learning approach, something that most first year students would have experienced for the first time, could have compounded the perceived difficulty. The course is being moved into the second semester to measure the role the flipped-learning approach had on these students.

The third objective was to ensure that the course included enough fundamentals not to impact future learning for programming related disciplines; the risk being linked to reduced difficulty or that students would struggle to integrate skills developed with MATLAB into other more powerful languages. The data analysed within the third-year course focused on C and Assembler suggesting that this approach is just as appropriate as the traditional method.

The final objective was to create balance between the first three objectives to ensure that the course would encourage student enrolment within the computer engineering discipline. The data showed that enrolment numbers within the discipline continued to increase in the second year.

Overall, the engineering problem solving approach was successful with all four objectives having positive outcomes. However, student achievement and experience was found to be somewhat correlated across the engineering disciplines based on the stereotypical assumptions of the relevance of programming to each discipline. The data suggests further 
refinement of the approach is needed including helping civil and mining majors appreciate the relevance of programming, and that the flipped learning and programming combination might have been too soon for these disciplines. Therefore, further refinement and research is needed. The findings of this paper can advance knowledge of how a programming course can be designed and implemented for an engineering common first year with relevant strengths and weaknesses identified and documented.

\section{References}

Anand, A., A. Kothiyal, B. Rajendran and S. Murthy. 2014. Guided problem solving and group programming: A technology-enhanced teaching-learning strategy for engineering problem solving. In Technology for Education (T4E), 2014 IEEE Sixth International Conference on, 126-33: IEEE.

Ashok Kumar, V., D.S. Daryl, L. Rolf and L. Mikko-Jussi. 2017. The impact of prior programming knowledge on lecture attendance and final exam. Journal of Educational Computing Research.

Berenguel, M., F. Rodríguez, J.C. Moreno, J.L. Guzmán and R. González. 2016. Tools and methodologies for teaching robotics in computer science \& engineering studies. Computer Applications in Engineering Education 24, no 2: 202-14.

Bodnar, C.A., D. Anastasio, J.A. Enszer and D.D. Burkey. 2016. Engineers at play: Games as teaching tools for undergraduate engineering students. Journal of Engineering Education 105, no 1: 147-200.

Cass, S. 2015. The 2015 top ten programming languages. IEEE Spectrum, July 20.

Cazzola, W. and D.M. Olivares. 2016. Gradually learning programming supported by a growable programming language. IEEE Transactions on Emerging Topics in Computing 4, no 3: 404-15.

Chi, M.T. and R. Wylie. 2014. The ICAP framework: Linking cognitive engagement to active learning outcomes. Educational Psychologist 49, no 4: 219-43.

Chilana, P.K., C. Alcock, S. Dembla, A. Ho, A. Hurst, B. Armstrong and P.J. Guo. 2015. Perceptions of non-cs majors in intro programming: The rise of the conversational programmer. In Visual Languages and Human-Centric Computing (VL/HCC), 2015 IEEE Symposium on, 251-59: IEEE.

Forte, A. and M. Guzdial. 2005. Motivation and nonmajors in computer science: Identifying discrete audiences for introductory courses. IEEE Transactions on Education 48, no 2: 248-53.

Frymier, A.B. and G.M. Shulman. 1995. "What's in it for me?": Increasing content relevance to enhance students' motivation. Communication Education 44, no 1: 40-50.

Gardner, A. P., K. Willey, K. Vessalas and J. Li. 2014. Experiences with flipped learning in subjects in consecutive stages of a civil engineering programme. In Australasian Association for Engineering Education Annual Conference 2014. Wellington.

Hahn, B. and D.T. Valentine. 2013. Essential MATLAB for engineers and scientists: Academic Press. 
Hastie, D.B., M. Ros, B. Stappenbelt and S. Kiridena. 2015. Development and implementation of a flipped-classroom delivery in engineering computing and analysis for first year engineering students. Paper presented at the 26th Annual Conference of the Australasian Association for Engineering Education.

Hoffbeck, J.P., H.E. Dillon, R.J. Albright, L. Wayne and T.A. Doughty. 2016. Teaching programming in the context of solving engineering problems. In 2016 IEEE Frontiers in Education Conference (FIE), 1-7.

Hulls, C., C. Rennick, S. Bedi, M. Robinson and W. Melek. 2015. The use of an open-ended project to improve the student experience in first year programming. Proceedings of the Canadian Engineering Education Association.

Hutchison-Green, M.A., D.K. Follman and G.M. Bodner. 2008. Providing a voice: Qualitative investigation of the impact of a first-year engineering experience on students' efficacy beliefs. Journal of Engineering Education 97, no 2: 177-90.

Isong, B. 2014. A methodology for teaching computer programming: First year students' perspective. International Journal of Modern Education and Computer Science 6, no 9: 15 .

Kori, K., M. Pedaste, Ä. Leijen and E. Tõnisson. 2016. The role of programming experience in ICT students' learning motivation and academic achievement. International Journal of Information and Education Technology 6, no 5: 331.

Koulouri, T., S. Lauria and R.D. Macredie. 2015. Teaching introductory programming: A quantitative evaluation of different approaches. ACM Transactions on Computing Education (TOCE) 14, no 4: 26.

Lahtinen, E., K. Ala-Mutka and H.-M. Järvinen. 2005. A study of the difficulties of novice programmers. In ACM Sigcse Bulletin, 14-18: ACM.

Lee, M.J.W., S. Nikolic, P.J. Vial, C. Ritz, W. Li and T. Goldfinch. 2016. Enhancing projectbased learning through student and industry engagement in a video-augmented 3-D virtual trade fair. IEEE Transactions on Education 59, no 4: 290 - 98.

Liebenberg, J., M. Huisman and E. Mentz. 2015. The relevance of software development education for students. IEEE Transactions on Education 58, no 4: 242-48.

Maher, M.L., C. Latulipe, H. Lipford and A. Rorrer. 2015. Flipped classroom strategies for CS education. In Proceedings of the 46th ACM Technical Symposium on Computer Science Education, 218-23: ACM.

Male, S.A. and D. Bennett. 2015. Threshold concepts in undergraduate engineering: Exploring engineering roles and value of learning. Australasian Journal of Engineering Education 20, no 1: 59-69.

Martínez, L.G., G. Licea, J.R. Juárez and L. Aguilar. 2014. Experiences using PSP and XP to support teaching in undergraduate programming courses. Computer Applications in Engineering Education 22, no 3: 563-69.

Mason, G.S., T.R. Shuman and K.E. Cook. 2013. Comparing the effectiveness of an inverted classroom to a traditional classroom in an upper-division engineering course. IEEE Transactions on Education 56, no 4: 430-35.

Mok, H.N. 2014. Teaching tip: The flipped classroom. Journal of Information Systems Education 25, no 1: 7.

Nikolic, S. and R. Raad. 2017. Designing and using self-paced tutorials: Lessons from the pilot. Paper presentat at the 28th Australasian Association for Engineering Education Annual Conference, in Sydney.

Nikolic, S., C. Ritz, P.J. Vial, M. Ros and D. Stirling. 2015a. Decoding student satisfaction: How to manage and improve the laboratory experience. IEEE Transactions on Education 58, no 3: 151-58. 
Nikolic, S., D. Stirling and M. Ros. 2018. Formative assessment to develop oral communication competency using YouTube: Self- and peer assessment in engineering. European Journal of Engineering Education 43, no 4: 538-551.

Nikolic, S., P.J. Vial, M. Ros, D. Stirling and C. Ritz. 2015b. Improving the laboratory learning experience: A process to train \& manage teaching assistants. IEEE Transactions on Education 58, no 2: 130-39.

Nyamapfene, A. and S. Lynch. 2016. Systematic integration of MATLAB into undergraduate mathematics teaching: Preliminary lessons from two uk institutions. In Global Engineering Education Conference (EDUCON), 2016 IEEE, 1145-48: IEEE.

O'Flaherty, J. and C. Phillips. 2015. The use of flipped classrooms in higher education: A scoping review. The Internet and Higher Education 25: 85-95.

Oreta, A.W.C. and A.P. Balili. 2015. Demonstrating students' skills on integrating knowledge of math and engineering in an applied programming course in civil engineering. Computer Applications in Engineering Education 23, no 4: 630-37.

Pears, A., S. Seidman, L. Malmi, L. Mannila, E. Adams, J. Bennedsen, M. Devlin and J. Paterson. 2007. A survey of literature on the teaching of introductory programming. SIGCSE Bull. 39, no 4: 204-23.

Radcliffe, P.J. and D. Kumar. 2016. Is problem-based learning suitable for engineering? Australasian Journal of Engineering Education 21, no 2: 81-88.

Rubio, M.A., C.M. Hierro and A. Pablo. 2013. Using Arduino to enhance computer programming courses in science and engineering. In Proceedings of EDULEARN13 conference, 5127-33.

Salama, G., S. Scanlon and B. Ahmed. 2017. An evaluation of the flipped classroom format in a first year introductory engineering course. In 2017 IEEE Global Engineering Education Conference (EDUCON), 367-74.

Shim, J., D. Kwon and W. Lee. 2017. The effects of a robot game environment on computer programming education for elementary school students. IEEE Transactions on Education 60, no 2: 164-72.

Tan, P.H., C.Y. Ting and S.W. Ling. 2009. Learning difficulties in programming courses: Undergraduates' perspective and perception. In 2009 International Conference on Computer Technology and Development, 42-46.

Tek, F.B., K.S. Benli and E. Deveci. 2018. Implicit theories and self-efficacy in an introductory programming course. IEEE Transactions on Education PP, no 99: 1-8.

Vial, P.J., S. Nikolic, M. Ros, D. Stirling and P. Doulai. 2015. Using online and multimedia resources to enhance the student learning experience in a telecommunications laboratory within an Australian university. Australasian Journal of Engineering Education 20, no 1: 71-80.

Vihavainen, A., J. Airaksinen and C. Watson. 2014. A systematic review of approaches for teaching introductory programming and their influence on success. In Proceedings of the tenth annual conference on international computing education research, 19-26: ACM.

Zhang, Y., Y. Dang and B. Amer. 2016. A large-scale blended and flipped class: Class design and investigation of factors influencing students intention to learn. IEEE Transactions on Education 59, no 4: 263-73. 